\title{
Pengembangan Waroeng Semawis Dalam Mendukung Wisata Kuliner Di Kota Semarang Provinsi Jawa Tengah
}

Gayuh Sherdianto a, 1 , I Putu Anom a, 2

${ }^{1}$ gsherdianto@gmail.com, ${ }^{2}$ putuanom@unud.ac.id

a Program Study Sarjana Destinasi Pariwisata, Fakultas Pariwisata,Universitas Udayana, Jl. Dr. R. Goris, Denpasar, Bali 80232 Indonesia

\section{Abstract}

The selection of this research topic is based on the seriousness of Semarang City Government to maximize the potential of culinary tourism. The development of culinary tourism is expected to support the existing tourism in Semarang City. In this study, the researchers chose WaroengSemawis as the main focus of the research location. WaroengSemawis is a culinary night market located in the Chinatown area in Semarang City. Initially,WaroengSemawis was just a Lunar New Year SemawisMarket held only days before the Lunar New Year day, but since 2004 WaroengSemawis became a regular event every weekend. There are many types of culinary available there, ranging from local cuisine to typical Chinese cuisine. In addition, there are also many historical Chinese temples surrounding WaroengSemawis area that have their own history as well.

The purpose of this research is to analyze the potential of culinary tourism and the development strategy of the culinary tourism particularly at WaroengSemawis in Semarang City. The data used in this research is the type of qualitative data, while the data source is primary data and secondary data. Data collection is done by observation, interview, literature study, and documentation. Data analysis technique used in this study is SWOT to find out what strategies can be used. The results of this study indicate that there are still some shortcomings that must be developed by the management of WaroengSemawis. The need of additional public toilets, parking lots, as well as the addition of traditional culinary or culinary types of Semarang. By increasing some of these facilities, it can help boosting the amenity and interest of tourists to visit WaroengSemawis so that it can leave a good impression on the tourists.

Keywords: Development Strategy, Culinary Tourism, Waroeng Semawis

\section{PENDAHULUAN}

Kota Semarang adalah sebuah ibukota dari Provinsi Jawa Tengah dimana banyak destinasi wisata yang menarik seperti bangunan bersejarah Lawang Sewu, Gereja Blendug kota lama hingga Klenteng Sam Poo Kong. Selain beberapa destinasi unggulan daiatas Kota Semarang memiliki daya tarik lainnya dalam bidang wisata kuliner. Beragamnya suku dan etnis yang ada di Kota Semarang membuat kota ini memiliki banyak makanan dan minuman khas, serta menjadi tersendiri bagi setiap wisatawan yang datang ke Kota Semarang. Kebanyakan wisatawan mengetahui kuliner khas Semarang seperti Lunpia, Kue Mochi, Wiingko Babat, Wedang Tahu, Mi Kopyok, Tahu Bakso serta Bandeng Presto. Beragam kuliner tersebut begitu terkenal di Semarang, dan dijadikan buah tangan wisatawan ketika ke tersebut.

Salah satu destinasi wisata kuliner di Kota semarang adalah Waroeng Semawis. Waroeng Semawis adalah pasar kuliner/foodcourt yang terkenal di Kota Semarang. Waroeng Semawis ini sudah berumur belasan tahun, sejak tahun 2004 yang berlokasi di kawasan Pecinan Semarang.
Dapat dijumpai ratusan stand yang merupakan penjual aneka makanan khas Semarangan, sampai makanan khas chinese. Jadi wisatawan takperlu jauh-jauh bolak-balik mencari mananan semaran diberbagai tempat, cukup disatu tempat saja dapat merasakan semuanya.

Meskipun demikian, focus pengembangan di waroeng semawis hanya sebatas pada bagaimana meningkatkan kuantitas wisatawan, tanpa mencoba memperbaiki kualitas wisata yang ada. Tren saat ini sesungguhnya membuat wisata kuliner naik daun karena tidak afdol apabila wisatawan mengunjungi sebuah destinasi tanpa merasakan nikmatnya makanan khas destinasi tersebut. Walaupun tak sedikit pula yang memandang wisata kuliner hanya pelengkap dalam kegiatan kepariwisataan, namun tren sudah menunjukkan pentingnya kuliner khas dalam sebuah destinasi. Berdasarkan latar belakang tersebut penelitian yang membahas topik strategi pengembangan wisata kuliner/makanan di Waroeng Semawis Kota Semarang perlu dilakukan atau diteliti. Tujuannyatentu saja adalah guna mengetahui strategi seperti apa yang dibutuhkan untuk 
mengembangkan wisata kuliner/makanan di waroeng semawis semarang.

\section{KEPUSTAKAAN}

\subsection{Telaah Hasil Penelitian Sebelumnya}

Penelitian pertama adalah skripsi dari Fajrii Kurniawan (2016) dengan judul "Potensi Wisata Kuliner Dalam Pengembangan Pariwisata Di Jogja". Penelitian Fajri menunjukkan bahwa wisata kuliner adalah sebuah wisata yang begitu potensial bagi pariwisata yogyakarta. Pemprov Jogja juga berusaha untuk mengembangkan potensi wisata kuliner di Jogja, Fastival Makanan Tradisional adalah salah satu contohnya. Persamaan peneilitian Fajri Kurniawan (2008) dengan penulis adalah pada focus peneitiannya dimana sama-sama mengenai pengembangan wisata kuliner, sementara letak perbedaanya adalah pada lokus/lokasi penelitian dimana Fajri meneliti di Kota Yogyakarta sementara penulis mengambil lokasi penelitian di Kota Semarang.

Telaah penelitian selanjutnya yaitu Jurnal oleh Pujiiyati dan Mita Harsana (2011) dengan judul "Studii Potensi Wisata Makanan (Food Tourism) Dalam Pengembangan Pariwisata Di Kota Semarang Provinsi Jawa Tengah". Persamaan penelitian tersebut dengan penelitian kali ini adalah mengangkat tema yang sama tentang wisata kuliner dan persamaan lokasi penelitian di ibukota jateng yakni Semarang. Perbedaan dari penelitian ini yaitu Pujiyanti dan Harsana lebih berfokus pada karakteristik dari wisatawan pada pasar wisata kuliner di Semarang. Sedangkan penulis lebih berfokus pada strategi pengembangan wisata kuliner.

\subsection{Landasan Konsep dan Teori Analisis}

1. Konsap Pengembangan Pariwisata

Paturusi (2001) mengemukakan bahwa pengembangan merupakan sebuah strategi guna meningkatkan, memajukan dan memperbaiki sektor kepariwisataan sebuah DTW sehingga mampu meningkatkan jumlah kunjungan serta berdampak positif kepada pemerintah hingga masyarakat lokal sekitar di daya tarik tersebut.

2. Konsep Wisata Kuliner.

Menurut ICTA yang merupakan sebuah asosiasi/perkumpulan pariwisata kuliner internasional dalam asosiasinya mereka mendefinisikan wisata kuliner merupakan kegiatan makan serta minum yang khas bagi setiap pengunjung/wisatawan yang sedang berwisata. Kemudian Hall dan Mitchell (2011) membagi wisata kuliner menjadi beberapa jenis yakni food festival, street food, produsen makanan dan restaurant.

3. Konsep Potensi Wisata.

"Potensi wisata sebagai kemempuan sebuah wilayah yang mungkin bisa dimanfaatkan guna pembengunan, mencakup alam dan manusia serta hasil karya manusia itu sendiri". Sujali (dalem Andani, 2008).

4. Konsep Prospek

Pengertian prospek adalah seorang individu, kelompok ataupun organisasi yang dianggap potensial oleh pemasar dan ingin terlibat dalam suatu pertukaran bisnis. Pendek kata, arti prospek adalah calon pembeli yang mempunyai keinginan terhadap suatu produk atau jasa tertentu. (Simamora : 2001)

5. Konsep Klasifikasi Makanan Indonesia

"Makanan Indonesia merupakan susunan makanan yang terdiri dari makanan pokok, lauk pauk, sayuran, sambal, sedapan, dan minuman (Handayanii, dan Marwanti, 2011). Pada prinsipnya makanan Indonesia dapat diklasifikasikan menjadi Hidangan Pokok, Hidangan Lauk Pauk, Hidangan Sayur, Sambal, Makanan Ringan, Minuman

6. Konsep Potensi Pendukung

Pendukung kegiatan (Activity Support) adalah meliputi seluruh pengguanaan dan aktifitas yang membantu memperkuat ruangruang umum, karena aktifitas dan fisik ruang selalu saling melengkapi satu sama lain. Bentuk, lokasi, dan karakteristik suatu areal tertentu akan menarik fungsi, penggunaan dan aktifitas spesifik (Shirvani, 1985). Dalam arti keberadaan dari potensi pendukung adalah sebagai salah satu elemen penghidup kegiatan diwarnai dengan karakter lingkungan yang terdiri dari berbagai fungsi dan keanekaragaman kegiatan.

7. Konsep Warung

Menurut kamus besar bahasa Indonesia (KBBI V) arti kata warung adalah tempat berjualan makanan, minuman, kelontong, dan sebagainya. Dapat disimpulkan bahwa warung adalah tempat untuk menjual makanan atau minuman yang dijual di tempattempat umum yang mudah dijangkau bagi para pembeli atau konsumen. Dan juga dengan 
pelayanan yang seadanya serta harga yang sangat terjangkau.

\section{Konsep Restoran}

Menurut Ninemeier dan Hayes (2006), Restoran adalah suatu operasi layanan makanan yang mendatangkan keuntungan yang mana basis utamanya termasuk di dalamnya adalah penjualan makanan / minuman kepada individu - individu dan tamu tamu dalam kelompok kecil.

\section{III.METODE PENELITIAN}

Penelitian ini dilakukan di Waroeng Semawis yang menjadi sasaran utama bagi para wisatawan yang sedang berkunjung di Kota Semarang. Waroeng Semawis berada di Jalan Gang Warung, Kranggan, Semarang Tengah, Kota Semarang atau yang biasa dikenal masyarakat Semarang dengan kawasan Pecinan. Metode yang diigunakan yaitu deskriptip kualitatif, yang mana jenis data yang digunakan adalah data kualitatip. Sementara sumber datanya yakni data primer mengenai strategi pengembangan waroeng semawis sebagai wisata kuliner di kota semarang, sementara data sekunder yaitu data pendukung seperti jumlah fasilitas, foto maupun data lain yang penulis dapatkan dari jurnal maupun peneilitian sebelumnya. Tekhnik pengumpulan data diilakukan melalui observasii, study litetarur serta wawencara beberapa informan seperti pelaku usaha kuliner, Dinas Pariwisata Kota Semarang, dan wisatawan di lokasi waroeng semawis. Teknik analisis data menggunakan analisis SWOT yang menghasilkan stratagi SO, stategi ST, strategii WO dan stretegi WT sebagai hasil akhirnya.

\section{HASIL DAN PEMBAHASAN}

\subsection{Gambaran Umum Waroeng Semawis}

Sejarah waroeng semawis dimulai sebelum tahun 2000 dimana daerah tersebut dinilai sebagai slum area atau daerah kumuh. Kemudian tahun 2004 dibuatlah kawasan waroeng semawis yang menjadi foodcourt di kota semarang.

Semawis sendiri berasal dari bahas jawa halus atau kromo inggil yang memiliki arti Kota Semarang. Jadi semawis adalah semarang.

Kawasan waroeng semawis sekarang dikelola dibawah naungan organisasi lokal yakni "Kopi Semawis", dikelola secara mandiri tanpa bantuan dari dinas pariwisata setempat.
Organisasi ini dibentuk pada tahun 2003 melalui surat keputusan wali kota semarang.

Waroeng semawis buka selamat tiga hari dalam satu minggu yakni disaat weekend. Hari jumat, sabtu minggu merupakan saat waroeng semawis beroperasi yang dimulai dari sore pukul 18.00 sampai malam menjelang dini hari.

\subsection{Strategi Pengembangan Wisata Kuliner Pada Waroeng Semawis}

Setelah dilakukan pengumpulan data kualitatif dari peneilitian, selanjutnya adalah dianalisis dengan menggunakan metode analisi SWOT. Dimana di bandingkan factor internel meliputi STRENGT dan WEAKNESS dengan factor eksternal meliputii THREATS dan OPPORTUNITIES :

a) Strength atau Kekuaatan

1) Banyak dijumpai kelenteng yang memiliki nilai historis tinggi di kawasan waroeng semawis.

2) Banyak atrkasi wisata lainnya selain wisata kuliner yang dapat memanjakan wiatawan.

3) Murah/terjangkaunya harga makanan dan minuman di waroeng semawis.

4) Kebersihan di waroeng semawis cukup baik dan terjaga.

b) Weakness atau Kalemahan

1. Parkir area yang kurang memadai.

2. Toilet umum pengunjung yang sangat terbatas.

3. Angkutan umum yang belum bisa menjangkau kawasan waroeng semawis

4. Rancunya pengaturan antara makanan halal dan non halal.

c) Opportunities atau Peluang

1) Banyak investor yang berniat menanamkan modal di Kota Semarang.

2) Masifnya pembangunan hotel yang dapat menjadi sarana akomodasi wisatawan di sekitar waroeng semawis.

3) Wisatawan banyak memiliki ketertarikan terhadap wisata budaya dan kuliner

4) Segmen pasar/wisatawan minat khusus banyak dijumpai di Kota Semarang.

d) Threat atau Anceman

1) Gencarnya pertumbuhan mall-mall disekitar kawasan pecinan waroeng semawis yang dapat menjadi pesaing. 
2) Hadirnya aplikasi pemesanan makanan online seperti go-food yang dapat menurunkan jumlah kunjungan.

3) Lokasi waroeng semawis yang outdoor sering terganggu akibat cuaca misalnya saat hujan.

4) Semakin sedikit pedagang yang khusus menjual makanan tradisional khas semarang.

Setelah dilakukan analisa dengan membandingkan/mengkelompokkan factor internal serta factor eksternal. Sehingga dapat dirumuskanlah beberapa strategi yang bisa dilakukan untuk mengembangkan wisata kuliner waroeng semawis kota semarang. Strategi dapat dilihatpada matriks tabel 4.1. sementara itu, berikut adalah penjelasan lebih rinci dari strategi yang telah ditetapkan :

\section{a. STRATEGI SO}

1) Menggandeng investor untuk membuat sebuah paket wisata. paket wisata dinilai penting karena diharapkan wisatawan yang datang ke waroeng semawis bisa melakukan aktivitas lainnya. Wisata kuliner tidak hanya melulu tentang makan, tetapi bisa juga diajak untuk mengetahui bagaimana proses pembuatannya hingga berjalan-jalan dikawasan pecinan yang memiliki 11 kelenteng dengan nilai historis tersendiri. Masyarakat lokal juga dapat diberdayakan menjadi guide lokal. (S1, S2 dan 01, 02, 03)

2) Menggalakkan promosi dengan gencar mengenai potensi dan keunggulan woreng semawis. Kondisi eksisting waroeng semawis yang bik dan bagusharus ipromosikan kepada para pengunjung. Harus meaykinkan bahwa waroeng semawis bersih dan nyaman, serta pedagang dapat memberikan list harga disetiap makanannya sehingga wisatawan lebih merasa aman(S3, S4, 04)

b. STRATEGI WO

1) Menggandeng berbagai pihak untuk menangani masalah parkir. Saat ini kondisi lahan parkir di waroeng semawis sangat terbatas dan mengenaskan. Organisasi kopi semawis selaku pengelola kawasan ini sudah sepantasnya mengambil langkah cepat untuk menangani permasalahn parkir dengan bekerjasama dengan pihak lain. (W1, W2 dan 01)

2) Penyediaan informasi makanan halal dan non halal di waroeng semawis. Hal tersebut harus dilakukan mengingat banyak wisatawan yang berkunjung ke waroeng semawis tidak hanya dari etnis tionghoa saja, namun juga wisatawan muslim serta beragam wisatawan lainnya. Sehingga dapat menghindari halhal yang tidak dinginkan. (W4 dan 04)

c. STRATEGI ST

1) Membangun kerjasama dengan Dinas Pariwisata Kota Semarang serta generasi muda untuk melakukan gerakan cinta budaya dan wisata lokal. Semakin maju perkembangan jaman semakin massif pula pembangunan mall-mall besar di kota semarang yang dikhawatirkan dapat menggerus usaha dan kuliner lokal. Dengan usaha tersebut keberadaan waroeng semawis diharapakn dapat terus bertahan melawan zaman.(S1 dan T1, T3)

2) Menyediakan brosur wisata kuliner di kawasan waroeng semawis dimana didalamnya berisi potret keragaman kuliner kota semarang. Brosur yang memuat apa saja makanan dan daya tarik di kawasan pecinan tersubut mampu menarik kunjungan wisatawan alih-alih hanya memesan makanan lewat aplikasi online semacam go-food. (S3 dan T2)

\section{d. STRATEGI WT}

1) Perlu banyak pembenahan berbagai fasilitas pendukung wisata di kawasan waroeng semawis. Pembenahan tersebut bertujuan untuk memanjakan wisatawan dan pengunjung yang datang ke waroeng semawis. (W1,W2, W3, dan T3)

2) Melestarikan dan menambah pedagang/stand makanan yang menjajakan kuliner khas kota semarang. Karena saat ini sudah semakin sedikit stand kuliner di waroeng semawis yang menjual makanan tradisional khas semarang. Dengan lestarinya makanan tradisional semarangan, dapat membuat waroeng semawis tetap bertahan dan memiliki keunikan tersendiri. (W4 dan T4) 
Tabel 4.1

\section{Matrik SWOT}

\begin{tabular}{|c|c|c|}
\hline EFAS & \begin{tabular}{lr}
\multicolumn{3}{c}{ Kekuatan (S) } \\
1. Banyak dijumpai \\
kelenteng yang \\
memiliki nilai \\
historis tinggi di \\
kawasan waroeng \\
semawis. \\
2. Banyak atrkasi \\
wisata lainnya selain \\
wisata kuliner yang \\
dapat memanjakan \\
wiatawan. \\
3. Murah/terjangkauny \\
a harga makanan \\
dan minuman di \\
waroeng semawis. \\
4. Kebersihan di \\
waroeng semawis \\
yang terjaga baik.
\end{tabular} & $\begin{array}{l}\text { Kelemahan }(\mathbf{W}) \\
\text { 1. Parkir area yang } \\
\text { kurang } \\
\text { memadai. } \\
\text { 2. Toilet umum } \\
\text { pengunjung } \\
\text { yang sangat } \\
\text { terbatas. } \\
\text { 3. Angkutan umum } \\
\text { yang belum bisa } \\
\text { menjangkau } \\
\text { kawasan } \\
\text { waroeng } \\
\text { semawis } \\
\text { 4. Rancunya } \\
\text { pengaturan } \\
\text { antara makanan } \\
\text { halal dan non } \\
\text { halal. }\end{array}$ \\
\hline Peluang (0) & Strategi SO & Strategi (W0) \\
\hline $\begin{array}{l}\text { 1. Banyak investor } \\
\text { yang berniat } \\
\text { menanamkan } \\
\text { modal di Kota } \\
\text { Semarang. } \\
\text { 2. Masifnya } \\
\text { pembangunan } \\
\text { hotel yang dapat } \\
\text { menjadi sarana } \\
\text { akomodasi } \\
\text { wisatawan } \\
\text { waroeng semawis. } \\
\text { 3. Wisatawan banyak } \\
\text { memiliki } \\
\text { ketertarikan } \\
\text { terhadap budaya } \\
\text { dan kuliner } \\
\text { 4. Segmen } \\
\text { pasar/wisatawan } \\
\text { minat khusus } \\
\text { banyak dijumpai } \\
\text { di Kota Semarang. }\end{array}$ & 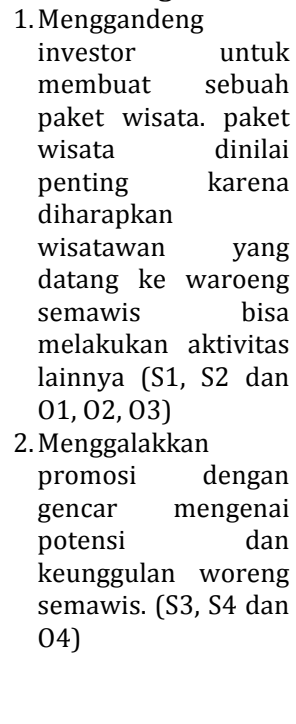 & $\begin{array}{l}\text { 1. Menggandeng } \\
\text { berbagai pihak } \\
\text { untuk } \\
\text { menangani } \\
\text { masalah parkir. } \\
\text { (W1, W2, dan } \\
\text { O1) } \\
\text { 2. Penyediaan } \\
\text { informasi } \\
\text { makanan halal } \\
\text { dan non halal di } \\
\text { waroeng } \\
\text { semawis. (W4 } \\
\text { dan 04) }\end{array}$ \\
\hline 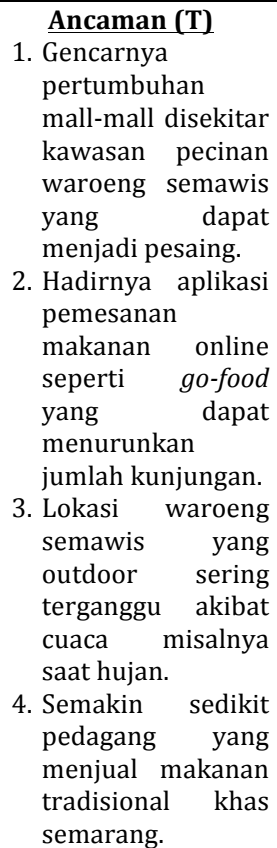 & $\begin{array}{l}\text { Strategi (ST) } \\
\text { 1. Membangun } \\
\text { kerjasama dengan } \\
\text { Dinas Pariwisata } \\
\text { Kota Semarang serta } \\
\text { generasi muda untuk } \\
\text { melakukan gerakan } \\
\text { cinta budaya dan } \\
\text { wisata lokal. (S1 dan } \\
\text { T1, T3) disang } \\
\text { 2. Menyediakan brosur } \\
\text { wisata kuliner di } \\
\text { kawasan waroeng } \\
\text { semawis dimana } \\
\text { didalamnya berisi } \\
\text { potret keragaman } \\
\text { kuliner kata } \\
\text { semarang. (S3 dan } \\
\text { T2) }\end{array}$ & $\begin{array}{l}\text { Strategi (WT) } \\
\text { 1. Perlu banyak } \\
\text { pembenahan } \\
\text { berbagai fasilitas } \\
\text { pendukung } \\
\text { wisata di } \\
\text { kawasan } \\
\text { waroeng } \\
\text { semawis. } \\
\text { (W1,W2, W3, } \\
\text { dan T3) } \\
\text { 2. Melestarikan } \\
\text { dan menambah } \\
\text { pedagang/stand } \\
\text { makanan yang } \\
\text { menjajakan } \\
\text { kuliner khas } \\
\text { kota semarang. } \\
\text { (W4 dan T4) }\end{array}$ \\
\hline
\end{tabular}

Sumber : hasil penelitian, 2018

\section{PENUTUP}

\subsection{Simpulan}

1. Straetegi Pangembangan Wisata Kuliiner di Waroeng Semawis

a. Strategi SO

1. Menggandeng investor untuk membuat sebuah paket wisata. paket wisata dinilai penting karena diharapkan wisatawan yang datang ke waroeng semawis bisa melakukan aktivitas lainnya. (S1, S2, 01, 02, 03)

2. Menggalakkan promosi dengan gencar mengenai potensi dan keunggulan woreng semawis. (S3, S4, 04)

b. Strategi WO

1. Menggandeng berbagai pihak untuk menangani masalah parkir. (W1,W2, 01)

2. Penyediaan informasi makanan halal dan non halal di waroeng semawis. (W4, 04)

c. Strategi ST

1. Membangun kerjasama dengan Dinas Pariwisata Kota Semarang serta generasi muda untuk melakukan gerakan cinta budaya dan wisata lokal. (S1, T1, T3)

2. Menyediakan brosur wisata kuliner di kawasan waroeng semawis dimana didalamnya berisi potret keragaman kuliner kota semarang. (S3, T2)

\section{d. Strategi WT}

1. Perlu banyak pembenahan berbagai fasilitas pendukung wisata di kawasan waroeng semawis. (S3, T2)

2. Melestarikan dan menambah pedagang/stand makanan yang menjajakan kuliner khas kota semarang. (W4, T4)

\subsection{Saran}

1. Bagi masyarakat lokal di sekitar kawasan waroeng semawis hendaknya mendukung pengembangan wisata kuliner dilokasi ini dengan beragam cara. Salah satu contohnya adalah menjaga lingkungan sekitar agar tetap bersih danmembuat wisatawan merasa aman dan nyaman.

2. Bagi kopi semawis selaku organisasi pengelola di kawasan waroeng semawis harus senantiasi berinovasi mengkikuti 
perkembangan zaman. Memperbaiki kondisi eksisting yang dirasa kurang. Bekerjsama dengan berbagai pihak baik dengan pemerintah maupun dengan investor.

3. Bagi pemerintah yang menjadi regulator agar senantiasa membantu pengembangan wisata kuliner di waroeng semawis ini dengan caranya sendiri misalnya memudahkan regulasi, bantuan dana maupun penyuluhan terhadap masyarakat lokal.

\section{DAFTAR PUSTAKA}

Andani, Suut. 2008. "Analisis Potensi Obyek Wisata Alam Pantai di Kabupaten. Gunung Kidul". Skripsi. Surakarta : Fakultas Geografi UMS. Badan Pusat Statistik.

Arikunto, Suharsimi. 2006. "Prosedur Penelitian Suatu Pendekatan Praktik”. Jakarta: Rineka Cipta.

Badan Pusat Statistik Provinsi Jawa Tengah. 2016. "Jumlah kunjungan wisatawan nusantara dan mancanegara di Kota Semarang".

Bungin, Burhan. 2007. "Penelitian Kualitatif: Komunikasi, Ekonomi, Kebijakan Publik, dan Ilmu Sosial Lainnya". Jakarta: Prenada Media Grup.

Daru Winartai. 1996. "Makanan Tradisional di DIY dan Sekitarnya". Dalam majalah Ilmu-ilmu Humaniora III, Yogyakarta; Gadjah Mada University Press.

Depdikbud. 2003. "Kamus Besar Bahasa Indonesia". Jakarta : Balai Pustaka.

Food and Agriculture Organization (FAO). 2001. "Pengertian dari Warung atau "Street Food".

Hall dan Mitchel. 2011. "Food Tourism Around the World: Development, Management, and Markets". Jakarta: Indo Salemba Empat.

Handayani, Titin Hera Widi dan Marwanti. 2011. "Modul Pengolahan Makanan Indonesia," Kementerian Pendidikan Nasional, Universitas Negeri Yogyakarta.

Kamus Besar Bahasa Indonesia (KBBI V). 2016. "Pengertian arti kata Warung".

Kurniawan, Fajri. 2008. "Potensi Wisata Kuliner Dalam Pengembangan Pariwisata Di Yogyakarta". Yogyakarta. (Skripsi).

Moleong, Lexi J. 2012. "Metodologi Penelitian Kualitatif". Bandung: PT. Renaja Rosdakarya.

Ninemeier, Hayes. 2006. "Restaurant Service by Managing The Environment Cornel Hotel \& Restaurant Administration Quarterly".

Paturusi, Samsul A. 2001, "Perencanaan Tata Ruang Kawasan Pariwisata, Materi Kuliah Perencanaan Kawasan Pariwisata," Program Pasca Sarjana Universitas Udayana Denpasar, Bali.

Pujiyati dan Minta Harsana. 2011. "Studi Potensi Wisata Makanan (Food Tourism) Dalam Pengembangan Pariwisata Di Kota Semarang Provinsi Jawa Tengah". Yogyakarta. (Jurnal).

Rangkuti, Freddy. 2011. "Analisi SWOT : Teknik Membedah Kasus Bisnis”. Jakarta: PT. Gramedia Pustaka Utama.
Republik Indonesia. 2009. "Undang-Undang Republik Indonesia No.10 Tahun 2009 Tentang Kepariwisataan".

Shirvani, Hamid. 1985. "Edition, illustrated. Publisher, Van Nostrand Reinhold". Original from, the University of Michigan.

Simamora, Bilson. 2001. "Memenangkan Pasar dengan Pemasaran Efektif dan. Profitabel". Edisi pertama. Jakarta: PT. Gramedia Pustaka Utama.

Sugiarto, Endar dan Sri Sulartiningrum. 1996. "Pengantar Industri Akomodasi dan. Restoran". Jakarta : Gramedia Pustaka Utama.

Sugiyono. 2014. "Metode Penelitian Kuantitatif Kualitatif dan R\&D". Bandung: Penerbit Alfabeta.

Winarno, Bondan. 2008. "Industri Kuliner Diusulkan Masuk dalam RUU Pariwisata", melalui http//www. Jajanan.com

Yoeti, Oka A. 2008. "Perencanaan dan Pengembangan Pariwisata". Jakarta: PT. Pradnya Paramita.

\section{SUMBER LAIN :}

https://jateng.bps.go.id/ diakses pada tanggal 16 Maret 2018

https://pemasaranpariwisata.com/2017/11/05/pemasar an-kepariwisataan-tourism-marketing/ diakses pada tanggal 16 Maret 2018

http://pariwisata.semarangkota.go.id/2018/frontend/we b/index.php diakses pada tanggal 13 Maret 2018

http://gastroina.blogspot.co.id/2016/02/profilindonesian-gastronomy-association.html diakses pada tanggal 30 Maret 2018

http://www.pengertianmenurutparaahli.net/pengertianprospek/ diakses pada tanggal 30 Maret 2018

https://waroengsemawis.wordpress.com/category/berita L diakses pada tanggal 26 Mei 2018

http://www.indonesian-publichealth.com/kriteria-sehatwarung-makan/diakses pada tanggal 5 Juni 2018 